Jos M. Latour

Johannes B. van Goudoever

Hugo J. Duivenvoorden

Nicolette A. M. van Dam

Eugenie Dullaart

Marcel J. I. J. Albers

Carin W. M. Verlaat

Elise M. van Vught

Marc van Heerde

Jan A. Hazelzet

\section{Perceptions of parents on satisfaction with care in the pediatric intensive care unit: the EMPATHIC study}

Received: 5 December 2008

Accepted: 21 March 2009

Published online: 15 April 2009

(C) The Author(s) 2009. This article is published with open access at Springerlink.com

\section{J. M. Latour · J. A. Hazelzet \\ Department of Pediatrics,}

Division of Pediatric Intensive Care,

Erasmus MC-Sophia Children's Hospital, P.O. Box 2060, 3000 CB Rotterdam,

The Netherlands

J. M. Latour · J. B. van Goudoever

Department of Pediatrics,

Division of Neonatology,

Erasmus MC-Sophia Children's Hospital,

Rotterdam, The Netherlands

\section{H. J. Duivenvoorden}

Department of Medical Psychology

and Psychotherapy,

Netherlands Institute for Health Science,

Erasmus Medical Center, Rotterdam,

The Netherlands

\section{N. A. M. van Dam}

Pediatric Intensive Care Unit,

Leiden University Medical Center,

Leiden, The Netherlands

E. Dullaart

Pediatric Intensive Care Unit,

Maastricht University Medical Center,

Maastricht, The Netherlands
M. J. I. J. Albers

Pediatric Intensive Care Unit,

Beatrix Children's Hospital,

University Medical Center Groningen,

Groningen, The Netherlands

\section{W. M. Verlaat}

Pediatric Intensive Care Unit,

University Medical Center St Radboud,

Nijmegen, The Netherlands

\section{E. M. van Vught}

Pediatric Intensive Care Unit, University Medical Center Utrecht-Wilhelmina

Children's Hospital, Utrecht,

The Netherlands

M. van Heerde

Department of Pediatric Intensive Care, VU University Medical Center, Amsterdam, The Netherlands

J. M. Latour (区)

Department of Pediatrics,

Division of Pediatric Intensive Care,

Erasmus MC-Sophia Children's Hospital,

Room Sp-1539, P.O. Box 2060,

3000 CB Rotterdam, The Netherlands

e-mail: j.latour@erasmusmc.nl

Tel.: +31-10-7037174

Fax: +31-10-7036796

\begin{abstract}
Purpose: To identify parental perceptions on pediatric intensive care-related satisfaction items within the framework of developing a Dutch pediatric intensive care unit (PICU) satisfaction
\end{abstract}

instrument. Methods: Prospective cohort study in tertiary PICUs at seven university medical centers in The Netherlands. Participants: Parents of 1,042 children discharged from a PICU. Results: A 78-item questionnaire was sent to 1,042 parents and completed by 559 (54\%). Seventeen satisfaction items were rated with mean scores $<8.0$ ( 1 , completely unimportant, to 10 , very important) with standard deviations $\geq 1.65$, and thus considered of limited value. The empirical structure of the items was in agreement with the theoretically formulated domains: Information, Care and Cure, Organization, Parental Participation, and Professional Attitude. The Cronbach's $\alpha$ of the domains ranged between 0.87 and 0.94. Conclusions: Parental perceptions on satisfaction with care measures were identified and prioritized. Reliabilities of the items and domains were of high level.

Keywords Family satisfaction . Pediatric intensive care unit . Parents - Experiences · Needs . Family-centered care . Quality of healthcare 


\section{Introduction}

Various approaches have been initiated to improve quality of care [1]. As generally accepted quality performance measurements were lacking, an international project defined a set of quality of healthcare indicators [2], including patient-centered care with empowerment of the patient and family. Consequently, patient satisfaction was then gradually recognized as an important tool to evaluate healthcare systems $[3,4]$.

Over the past few decades, integration of patient and family perspectives in clinical practice evolved slowly. There were some early initiatives concentrating on the needs of patient and family members, but the evaluation tools used did not always take into account their experiences [5-8]. Researchers started to develop instruments to explore user experiences with intensive care a few years ago, but only a few reliable family satisfaction surveys claim to be driven by patient and family experiences [913]. It would seem that continuous assessment of patient satisfaction as a quality performance indicator has not yet been widely accepted [14].

Similar to adult intensive care units, PICUs tend to concentrate on clinical outcome parameters such as mortality, morbidity, length of stay or survival outcomes to justify quality of care. Emphasizing partnership between parents and healthcare professionals, the PICUs in The Netherlands have recognized parental satisfaction as a quality performance indicator. This collaborative decision resulted in the multicenter Empowerment of Parents in the Intensive Care (EMPATHIC) study, a multiphase project designed to develop and implement a PICU parent satisfaction instrument. The study started with identifying satisfaction items described in the literature [15]. The next phase was a descriptive study on perceptions of nurses and physicians working in the PICUs [16]. In the present study we explored how parents perceived the identified satisfaction with care issues. The objectives were twofold: (1) to assess perceptions of parents who had experienced a PICU admission of their child on parental satisfaction issues, and (2) to perform factor analysis to evaluate the satisfaction items within domains.

\section{Methods}

The study was designed as a multicenter prospective cohort study. Seven of the eight multidisciplinary PICUs in The Netherlands participated in the study. All PICUs are level III tertiary referral centers with the capacity to provide transport facilities, (non)invasive ventilation, support multisystem failure management, postsurgical care, and other complex procedures and interventional care. Number of beds per PICU ranges from 8 to 24 . The annual total number of admissions is approximately
4,500. In 2005 the median age of admitted children was 1.8 years $\left(\mathrm{P}_{25-75} 0.3-7.8\right.$ years), the median length of stay was 3 days ( $\mathrm{P}_{25-75} 2-6$ days), and $55.8 \%$ were mechanically ventilated [17]. One 14-bed PICU, with approximately 600 yearly admissions, did not participate because the parents were already involved in another study. The study protocol was approved initially by the medical ethical review board of the Erasmus Medical Center in Rotterdam and subsequently by the review boards of the participating centers.

\section{Participants}

The study population consisted of parents or legal caretakers of children discharged from a PICU in the period July through October 2007. No minimum stay was defined, because the overall aim of the project was to develop a satisfaction instrument for all parents. Excluded from the study were parents whose child had died, either during PICU admission or after discharge from the PICU, and parents of children who had been readmitted in the study period (Fig. 1). The rationale for excluding parents of children who had died was the assumption that other research methods would be more appropriate for this group [18-20]. In the eventuality of transferral from one to another PICU, the parents' opinion was sought for the first admission only.

Ethnicity was determined by checking the child's first and family name using the combined name method [21]. Ethnicity was categorized into Dutch and non-Dutch.

\section{Questionnaire}

In a previous Delphi study, a self-administered questionnaire had been developed from literature data and opinions of nurses and physicians in eight PICUs [16]. The questionnaire included 78 items of satisfaction with care in five domains: Information, Care and Cure,

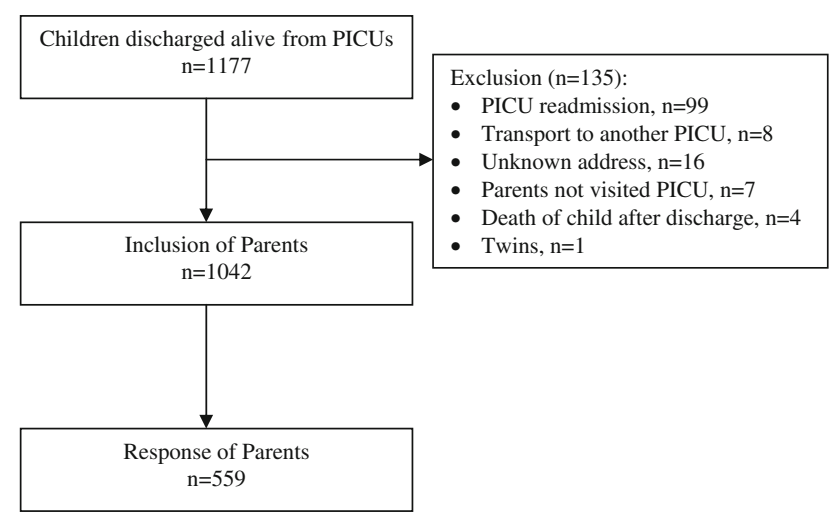

Fig. 1 Flowchart of the inclusion of study participants 
Organization, Parental Participation, and Professional Attitudes. Based on the empirical data of the nurses and physicians, factor analysis showed that 72 items had standardized factor loadings above 0.50 . The Cronbach's $\alpha$ of the domains varied from 0.74 to 0.92 .

Parents received a letter explaining the aim and content of the study 2-3 weeks after discharge. Attached were the above-mentioned questionnaire, a consent form, and a post-paid reply envelope. Parents were asked to rate the importance of the items. The rating scale was a tenpoint scale ranging from 1, completely unimportant, to 10, extremely important. An open-ended question was included asking for any comments. As The Netherlands is a multicultural society, the questionnaire was available, apart from in Dutch, in Arabic, Turkish, and English. Parents could obtain translated versions by returning a reply slip in three languages included in the invitation letter. The Dutch and English versions were also available online at www.empathic.nl through an individual code provided in the invitation letter.

\section{Statistical analysis}

Descriptive statistics were used to calculate mean scores and standard deviations of the satisfaction items for ranking the importance of the satisfaction items. Importance was defined as the highest mean and the smallest standard deviation.

Each center provided data of the participating children via the Pediatric Intensive Care Evaluation database. Anonymity was protected by coding. Distribution-free tests, i.e., the Mann-Whitney test for two independent samples and the $\chi^{2}$ test, served to compare characteristics of respondents and nonrespondents.

The empirical data of the parents were subjected to factor analysis aimed at identifying and estimating the dimensional structure and importance of individual items within that structure. Confirmatory factor analysis (CFA) was chosen instead of explorative factor analysis because the latter has limitations in statistical testing. In addition, the adequacy of model fit could be tested on statistical plausibility. The performance measures applied were the $\chi^{2}$ test of model fit and the $\chi^{2}$ test of model of fit for the baseline model. Values of $\chi^{2}, P$ values, and degrees of freedom $(d f)$ were scrutinized. For an adequate model fit the $\chi^{2}$ test of model fit had to be nonsignificant, which meant that the identified model adequately represented the interrelationship of data, the so-called observed correlation matrix. The reproduced correlation matrix, calculated from the identified model, must closely correspond to the observed correlation matrix. The ratio of $\frac{\chi^{2}}{d f}<1.5$ would represent a good model fit. Other tests used for the model fit were: comparative fit index (preferably CFI $>0.95$ ), Tucker-Lewis index (preferably TLI $>0.95$ ), root-mean-square error of approximation (preferably
RMSEA $\approx 0.05)$, and the weighted root-mean-square residual (preferably WRMR $<1.00$ ) [22].

As a measure of relative importance of the individual items, the standardized factor loadings, theoretically varying from -1 to +1 , are presented. Reliabilities of the domains were estimated by Cronbach's $\alpha$, with theoretically a maximum value of 1.0 .

The data were analyzed using SPSS (version 15, Chicago, USA) and the statistical modeling program Mplus (version 5, 2007, Los Angeles, USA).

\section{Results}

In the 4-month data collection period 1,177 children were discharged alive from the participating PICUs. Parents of 1,042 children were eligible to participate in the study. A total of 559 parents $(54 \%)$ completed the questionnaire (Fig. 1). The response rate per center ranged between $49 \%$ and $60 \%$. No more than 34 parents $(3 \%)$ completed the questionnaire online. Only three requests were received for translated versions: one for the Arabic version and two for the Turkish version. Most children were Dutch $(n=805,77.3 \%)$. In the non-Dutch group $(n=237), 47$ $(4.5 \%)$ were Turkish, $70(6.7 \%)$ were Moroccan, 43 $(4.1 \%)$ were Surinamese, and $77(7.4 \%)$ were categorized as "other". Characteristics of the children in the response and nonresponse groups are presented in Table 1. Significant differences between these groups were noted for ethnicity, PICU admission (unplanned versus planned), and number of ventilation days.

Table 2 presents the mean score and standard deviation (SD) for the individual items; they are ranked per domain on the highest mean and lowest standard deviation. The item "Caregivers give the highest priority to the child's health" was ranked as most important. Parents felt an organizational issue to be least important: "A locker on the PICU is available for all parents." For 17 satisfaction items the mean score was below eight. This cut-off point was determined from the empirical data due to lack of scientific rationale. The standard deviations of these 17 items exceeded 1.65 (Table 2). Six were related to information giving, in particular the accessibility and manner of information giving. The mean scores of the domains were: Information 8.64 (SD 0.86); Care and Cure 8.92 (SD 0.88); Organization 8.36 (SD 1.07); Parental Participation 8.39 (SD 1.11); Professional Attitude 8.72 (SD 0.91).

Parents of the non-Dutch group rated two culturalrelated items with higher means than did the parents of the Dutch group. The first item concerned the use of interpreters or interpreter-telephone services: mean 8.09, SD 2.24 versus mean 7.86 , SD $2.26(P=0.43)$. The second item was the alertness of the cultural background of child and parents; mean 8.19 , SD 1.71 versus mean 7.71, SD $2.04(P=0.03)$. 
Table 1 Characteristics of the children

\begin{tabular}{|c|c|c|c|c|c|}
\hline & Response $n$ & Response & Nonresponse $n$ & Nonresponse & $P$ \\
\hline Gender & & & & & 0.20 \\
\hline Male & 327 & $52.2 \%$ & 300 & $47.8 \%$ & \\
\hline Female & 232 & $56.2 \%$ & 181 & $43.8 \%$ & \\
\hline Age in months; median $\left(\mathrm{P}_{25-75}\right)$ & 558 & $29(4-115)$ & 479 & $28(5-91)$ & 0.85 \\
\hline Ethnicity & & & & & $<0.01$ \\
\hline Dutch & 483 & $60.0 \%$ & 322 & $40.0 \%$ & \\
\hline Non-Dutch & 76 & $32.1 \%$ & 161 & $67.9 \%$ & \\
\hline PICU admission & & & & & 0.01 \\
\hline Unplanned & 279 & $50.3 \%$ & 276 & $49.7 \%$ & \\
\hline Planned & 279 & $57.9 \%$ & 203 & $42.1 \%$ & \\
\hline Type of admission & & & & & 0.13 \\
\hline Surgical & 321 & $55.9 \%$ & 253 & $44.1 \%$ & \\
\hline Medical & 237 & $42.5 \%$ & 226 & $47.2 \%$ & \\
\hline Length of PICU stay in days; median $\left(\mathrm{P}_{25-75}\right)$ & 558 & $3(2-6)$ & 479 & $3(2-5)$ & 0.07 \\
\hline Ventilation days; median $\left(\mathrm{P}_{25-75}\right)$ & 550 & $1(0-3)$ & 468 & $0(0-2)$ & 0.02 \\
\hline Mortality risk PRISM 2; median $\left(\mathrm{P}_{25-75}\right)$ & 558 & $0.02(0.01-0.04)$ & 478 & $0.02(0.01-0.05)$ & 0.11 \\
\hline Mortality risk PIM 2; median $\left(\mathrm{P}_{25-75}\right)$ & 558 & $0.01(0.01-0.03)$ & 478 & $0.01(0.01-0.03)$ & 0.40 \\
\hline
\end{tabular}

Total numbers of respondents and nonrespondents vary on indi- PICU pediatric intensive care unit, PRISM pediatric risk of morvidual characteristics due to missing data; percentages are tality, PIM pediatric index of mortality presented in row percentages; $\chi^{2}$ test for categorical data; Mann-

Whitney test for nonparametric data

Table 2 Mean, standard deviation, standardized factor loadings, and reliability estimates of the satisfaction items

\begin{tabular}{|c|c|c|c|c|c|}
\hline & $\hat{\mu}$ & $\hat{\sigma}$ & $\begin{array}{l}\text { Factor } \\
\text { loadings }\end{array}$ & $\begin{array}{l}\text { Corrected } \\
\text { item-total } \\
\text { correlation }\end{array}$ & $\begin{array}{l}\text { Cronbach's } \\
\alpha \text { if item } \\
\text { deleted }\end{array}$ \\
\hline \multicolumn{6}{|l|}{ Information-Care } \\
\hline Parents are informed about the child's illness & 9.54 & 0.88 & 0.66 & 0.78 & 0.89 \\
\hline $\begin{array}{l}\text { Parents are informed about changes in the child's condition as soon } \\
\text { as possible }\end{array}$ & 9.53 & 0.91 & 0.52 & 0.75 & 0.89 \\
\hline Parents are informed about tests and procedures & 9.52 & 0.89 & 0.91 & 0.83 & 0.89 \\
\hline Caregivers inform the parents about the treatment consequences & 9.51 & 0.90 & 0.91 & 0.83 & 0.89 \\
\hline Caregivers answer parents' questions adequately & 9.40 & 0.96 & 0.77 & 0.67 & 0.90 \\
\hline Parents are informed about the child's future perspectives & 9.21 & 1.34 & 0.82 & 0.68 & 0.90 \\
\hline Parents are informed about the (adverse) effects of the medication & 9.20 & 1.23 & 0.95 & 0.74 & 0.89 \\
\hline Caregivers give no conflicting information to the parents & 9.15 & 1.42 & 0.81 & 0.57 & 0.91 \\
\hline \multicolumn{6}{|l|}{ Information-Accessibility } \\
\hline Caregivers daily inform parents about the child's care and treatment & 9.35 & 1.11 & 0.38 & 0.41 & 0.78 \\
\hline Parents have easy access to information & 8.99 & 1.25 & 0.91 & 0.43 & 0.78 \\
\hline The way to the PICU is clearly signposted & 7.96 & 1.66 & 0.76 & 0.55 & 0.76 \\
\hline Parents are informed about PICU rules & 7.95 & 1.66 & 0.59 & 0.61 & 0.75 \\
\hline $\begin{array}{l}\text { Caregivers' communication with non-Dutch-speaking parents is } \\
\text { through an interpreter or the interpreter-telephone service }\end{array}$ & 7.89 & 2.26 & 0.56 & 0.46 & 0.78 \\
\hline Caregivers provide not only oral but also written information & 7.75 & 1.84 & 0.47 & 0.57 & 0.76 \\
\hline Caregivers inform the parents on the best moment for the parents & 7.73 & 1.88 & 0.78 & 0.46 & 0.78 \\
\hline Parents are informed about sanitary units & 6.99 & 2.09 & 0.74 & 0.58 & 0.76 \\
\hline \multicolumn{6}{|l|}{ Care and Cure } \\
\hline Caregivers know their profession & 9.56 & 0.99 & 0.82 & 0.59 & 0.94 \\
\hline The correct medication is given at the right times & 9.50 & 0.98 & 0.85 & 0.67 & 0.94 \\
\hline Caregivers react promptly to changes in the child's condition & 9.47 & 1.02 & 0.75 & 0.70 & 0.94 \\
\hline Pain is prevented and/or treated & 9.44 & 0.96 & 0.74 & 0.64 & 0.94 \\
\hline $\begin{array}{l}\text { Caregivers jointly pursue one goal: adequate care and treatment } \\
\text { of child and parents }\end{array}$ & 9.27 & 1.04 & 0.78 & 0.70 & 0.94 \\
\hline Caregivers are aware of the child's medical history & 9.22 & 1.21 & 0.88 & 0.67 & 0.94 \\
\hline $\begin{array}{l}\text { Parents know which physician and nurse are responsible for the care } \\
\text { of their child }\end{array}$ & 9.11 & 1.23 & 0.78 & 0.67 & 0.94 \\
\hline At discharge, caregivers provide clear information to colleagues & 9.07 & 1.38 & 0.73 & 0.63 & 0.94 \\
\hline Caregivers are alert to the child's comfort & 9.05 & 1.12 & 0.83 & 0.66 & 0.94 \\
\hline $\begin{array}{l}\text { An assigned physician and nurse serve as contacts for the parents } \\
\text { during prolonged ICU stay }\end{array}$ & 8.97 & 1.32 & 0.74 & 0.60 & 0.94 \\
\hline Caregivers display a caring attitude towards child and parents & 8.88 & 1.26 & 0.79 & 0.78 & 0.94 \\
\hline
\end{tabular}


Table 2 continued

\begin{tabular}{|c|c|c|c|c|c|}
\hline & $\hat{\mu}$ & $\hat{\sigma}$ & $\begin{array}{l}\text { Factor } \\
\text { loadings }\end{array}$ & $\begin{array}{l}\text { Corrected } \\
\text { item-total } \\
\text { correlation }\end{array}$ & $\begin{array}{l}\text { Cronbach's } \\
\alpha \text { if item } \\
\text { deleted }\end{array}$ \\
\hline Caregivers prepare child and parents for a PICU admission & 8.79 & 1.29 & 0.76 & 0.70 & 0.94 \\
\hline Caregivers are alert to the child's developmental growth & 8.68 & 1.34 & 0.79 & 0.69 & 0.94 \\
\hline Caregivers are considerate to the child's wishes & 8.62 & 1.35 & 0.88 & 0.66 & 0.94 \\
\hline Caregivers provide emotional support to child and parents & 8.56 & 1.41 & 0.76 & 0.75 & 0.94 \\
\hline Parents are adequately prepared for the child's discharge & 8.53 & 1.45 & 0.60 & 0.62 & 0.94 \\
\hline Caregivers work in team with a strong group cohesion & 8.53 & 1.48 & 0.57 & 0.51 & 0.94 \\
\hline Caregivers adequately meet the needs of the parents & 8.17 & 1.49 & 0.80 & 0.70 & 0.94 \\
\hline A caregiver always advises parents during acute admission or an acute situation & 8.05 & 1.65 & 0.57 & 0.65 & 0.94 \\
\hline \multicolumn{6}{|l|}{ Organization } \\
\hline The PICU is clean & 9.18 & 1.21 & 0.72 & 0.56 & 0.91 \\
\hline The child's bed is clean & 9.12 & 1.16 & 0.75 & 0.61 & 0.91 \\
\hline The PICU is well accessible by phone & 9.11 & 1.28 & 0.74 & 0.61 & 0.91 \\
\hline Moment of discharge is not influenced by bed capacity & 9.10 & 1.33 & 0.77 & 0.46 & 0.91 \\
\hline Rooming-in near the PICU is possible & 9.01 & 1.54 & 0.71 & 0.47 & 0.91 \\
\hline The caregivers are efficiently organized & 8.86 & 1.23 & 0.72 & 0.62 & 0.91 \\
\hline Visiting hours are flexible & 8.59 & 1.67 & 0.76 & 0.48 & 0.91 \\
\hline Noise in the PICU is muffled as far as possible & 8.42 & 1.59 & 0.75 & 0.68 & 0.91 \\
\hline The PICU is imbued with a sense of safety & 8.40 & 1.49 & 0.74 & 0.69 & 0.91 \\
\hline The PICU's design is child-friendly & 8.38 & 1.61 & 0.77 & 0.64 & 0.91 \\
\hline Written information on unit rules, diseases, and procedures is available on the PICU & 8.38 & 1.66 & 0.74 & 0.65 & 0.91 \\
\hline The child's bed space is ample enough & 8.18 & 1.71 & 0.58 & 0.72 & 0.91 \\
\hline The PICU has comfortable furniture & 7.30 & 1.90 & 0.60 & 0.68 & 0.91 \\
\hline The waiting room is fitted out comfortably & 7.27 & 1.96 & 0.64 & 0.71 & 0.91 \\
\hline Catering for parents is well taken care of & 6.78 & 2.38 & 0.75 & 0.63 & 0.91 \\
\hline A locker on the PICU is available for all parents & 6.67 & 2.45 & 0.74 & 0.65 & 0.91 \\
\hline \multicolumn{6}{|l|}{ Parental participation } \\
\hline Parents trust the caregivers & 9.41 & 0.97 & 0.74 & 0.50 & 0.86 \\
\hline Home care aspects are discussed before discharge & 9.06 & 1.25 & 0.81 & 0.64 & 0.85 \\
\hline Caregivers stimulate parents to stay close to their child during procedures and tests & 8.77 & 1.46 & 0.77 & 0.62 & 0.85 \\
\hline Caregivers stimulate parents to be close to their child & 8.58 & 1.58 & 0.64 & 0.63 & 0.85 \\
\hline Parents share in decision-making on the care and treatment of their child & 8.57 & 1.57 & 0.79 & 0.56 & 0.86 \\
\hline Caregivers facilitate parents in expressing their feelings & 7.91 & 1.65 & 0.64 & 0.67 & 0.85 \\
\hline At admission caregivers ask parents their expectations & 7.74 & 1.80 & 0.79 & 0.65 & 0.85 \\
\hline Caregivers regularly inform after parental experiences during the course of admission & 7.58 & 1.97 & 0.69 & 0.67 & 0.85 \\
\hline Parents receive and are suggested to keep a diary & 7.04 & 2.33 & 0.77 & 0.57 & 0.86 \\
\hline \multicolumn{6}{|l|}{ Professional attitude } \\
\hline Caregivers give the highest priority to the child's health & 9.69 & 0.73 & 0.64 & 0.53 & 0.88 \\
\hline Caregivers adopt principles of hygiene & 9.51 & 0.87 & 0.75 & 0.57 & 0.88 \\
\hline Caregivers provide equal care, irrespective of race, religion, sex, and education & 9.36 & 1.14 & 0.74 & 0.59 & 0.87 \\
\hline $\begin{array}{l}\text { Regardless of work pressure the caregivers' attention towards child and parents is not } \\
\text { allowed to slacken }\end{array}$ & 9.18 & 1.09 & 0.87 & 0.64 & 0.87 \\
\hline Caregivers respect the child and parents & 9.14 & 1.15 & 0.61 & 0.69 & 0.87 \\
\hline Child and parents feel welcome at admission & 9.06 & 1.25 & 0.85 & 0.67 & 0.87 \\
\hline Caregivers refrain from unnecessary discussions at the child's bedside & 9.03 & 1.40 & 0.84 & 0.63 & 0.87 \\
\hline Staff always work agreeably together & 8.89 & 1.28 & 0.79 & 0.70 & 0.87 \\
\hline Caregivers safeguard privacy of child and parents & 8.83 & 1.23 & 0.80 & 0.64 & 0.87 \\
\hline Caregivers introduce themselves with name and position & 8.62 & 1.38 & 0.68 & 0.58 & 0.87 \\
\hline Caregivers show empathy to child and parents & 8.54 & 1.32 & 0.66 & 0.65 & 0.87 \\
\hline Caregivers are alert to the cultural background of the child and parents & 7.77 & 2.00 & 0.80 & 0.53 & 0.88 \\
\hline Caregivers pay attention to siblings & 7.46 & 2.04 & 0.51 & 0.53 & 0.88 \\
\hline Parents are offered religious/spiritual support & 6.98 & 2.35 & 0.79 & 0.40 & 0.89 \\
\hline
\end{tabular}

$\hat{\mu}$ mean, $\hat{\sigma}$ standard deviation, $P I C U$ pediatric intensive care unit

Altogether $203(36.3 \%)$ parents commented in identified from the qualitative data. Comments generally response to the open-ended question. Of these, $37 \mathrm{com}-$ complemented the items in the questionnaire. For examments were words of thank to the PICU team. The ple, "What surprised us was the limited space around the remaining comments were analyzed by two researchers bed, and a lot of, in our view, moving of the beds. As (J.M.L., B.E.-S.) comparing the parental narratives with parents you soon feel yourself in the way. Annoying were the topics of the questionnaire. No additional items were the noise and open discussions across the whole unit 
Table 3 Performance of the models

\begin{tabular}{lcccccccccc}
\hline Domains & Item no. & \multirow{2}{*}{$n$} & \multicolumn{2}{l}{ Chi-square test of model fit } & & \\
\cline { 5 - 10 } & & & & Value & $d f$ & $P$-Value & CFI & TLI & RMSEA & WRMR \\
\hline Information: Care and Accessibility & 16 & 559 & 1031.67 & 35 & 0.01 & 0.90 & 0.94 & 0.23 & 2.70 \\
Care and Cure & 19 & 559 & 646.90 & 58 & 0.01 & 0.90 & 0.97 & 0.14 & 1.59 \\
Organization & 16 & 551 & 943.67 & 42 & 0.01 & 0.82 & 0.93 & 0.20 & 2.19 \\
Parental Participation & 9 & 557 & 427.81 & 15 & 0.01 & 0.88 & 0.93 & 0.23 & 1.91 \\
Professional Attitude & 14 & 557 & 745.57 & 42 & 0.01 & 0.87 & 0.96 & 0.17 & 1.73 \\
\hline
\end{tabular}

$d f$ degrees of freedom, CFI comparative fit index; TLI Tucker-Lewis index, RMSEA root-mean-square error of approximation, WRMR weighted root-mean-square residual

about patients" [respondent 233-038]. This quote was categorized to four satisfaction items related to bed space, noise levels, unnecessary discussions at the bed side, and privacy protection.

Confirmatory factor analysis showed that four items did not fit the empirical structure of the domains to which the items belonged. These items were removed from the empirical structure for further analysis. Furthermore, four domains appeared to be unidimensional. The Information domain was two dimensional, with items specifically related to the dimensions Care and Accessibility (Table 2).

Although the model fits of the factor structures of the domains were weak (Table 3), the standardized factor loadings of the individual items were adequate with values above 0.50 except for one item, "Caregivers daily inform parents about the child's care and treatment" (0.38). Reliability was estimated for both the items and the domains (Tables 2,4). On the domain level, the reliabilities (estimated by Cronbach's $\alpha$ ) for five of the six domains were above 0.80 . The sixth domain, InformationAccessibility, had a Cronbach's $\alpha$ of 0.79 , which might still be qualified as acceptable. The corrected item-total correlations for the domains varied from 0.4 to 0.83 . As a measure of internal consistency, the values of Cronbach's $\alpha$ were above 0.85 , with the exception of all items in the domain Information-Accessibility (Table 2).

\section{Discussion}

Intensive care professionals are increasingly concerned about patient and family-centered care and involving family members in the care of the patient. In addition, the past decade showed an increase in explorative studies on perceptions of patient and family member. Both have led to the issuing of clinical practice guidelines on familycentered care in intensive care units [23]. It is debatable whether healthcare providers have truly gone along with these recommendations [6, 24]. Assessment of parental experiences would elucidate the extent to which familycentered care corresponds to the parental expectations.
Table 4 Descriptives and reliability estimates for domains

\begin{tabular}{lllrrl}
\hline Domains & Items no. & $n$ & $\hat{\mu}$ & \multicolumn{1}{l}{$\hat{\sigma}$} & $\alpha$ \\
\hline Information-Care & 8 & 545 & 75.05 & 6.80 & 0.91 \\
Information-Accessibility & 8 & 511 & 64.70 & 8.85 & 0.79 \\
Information (Total) & 16 & 503 & 139.83 & 13.53 & 0.87 \\
Care and Cure & 19 & 510 & 170.93 & 16.41 & 0.94 \\
Organization & 16 & 514 & 132.80 & 17.48 & 0.91 \\
Parental Participation & 9 & 526 & 74.78 & 10.22 & 0.87 \\
Professional Attitude & 14 & 528 & 122.03 & 12.64 & 0.88 \\
\hline
\end{tabular}

$\hat{\mu}$ mean, $\hat{\sigma}$ standard deviation, $\alpha$ Cronbach's alpha

Standardized parental satisfaction outcomes may then ultimately provide interventions to improve clinical practice. The parents in our study classified the importance of satisfaction measures, providing insight into their perceptions and experiences.

Several studies have provided state-of-the-art knowledge of parental needs in the PICU, as established by the modified 45-item Critical Care Family Needs Inventory [25-28]. The top 20 needs in these studies tend to focus on information provision, such as information on illness, progress, prognosis, and "knowing what is being done" [29]. Similar findings were reported in a systematic review of 115 articles on families with critically ill children [30]. Nevertheless, the authors concluded that most reports were anecdotal, often had small sample size, and that some showed methodological flaws.

Our data set of 78 satisfaction items covered a wider range of care aspects than only the parental needs. The large sample in our study rated several items in all domains very highly, indicating that issues other than just receiving adequate information at the right moment are important. Not surprisingly, the child's care is of importance to them, as well as behavior and attitude of the healthcare professionals. Some of these issues emerged also from a recent qualitative study among 20 parents of hospitalized children: 11 in a PICU and 9 in a general ward [31]. Parents of children in the PICU had more stress, and this affected their psychological outcomes. Importantly, stress factors were related to the severity of the child's illness, varying from admission to post discharge. This implication strengthens our aim to develop a 
core set of satisfaction items that covers the entire PICU stay, including the discharge process.

The widely used Parental Stressor Scale: PICU, developed by Carter and Miles [32], is a valuable tool to study parental stressors. Two small studies using this instrument demonstrated that the child having to undergo procedures or tests, the child having an endotracheal tube, and overall experiences in the PICU are the most important stressors for mothers $(n=31)$ and fathers $(n=15)[33,34]$. Furthermore, particularly mothers stated that receiving information from too many professionals is highly stressful. In this respect, the Creating Opportunities for Parent Empowerment (COPE) program offers a structured information intervention and directs parental participations [35]. In the study by Melnyk et al., mothers in the COPE program group reported significant less stress [35]. Regrettably, satisfaction was not considered as an outcome measure. For deeper understanding of parental experiences of a PICU admission, it might be advisable to combine a satisfaction survey with a stressor scale. Findings from such an approach might guide professionals towards combined interventions aimed at decreasing stress levels among parents, possibly resulting in higher satisfaction outcomes.

Availability of a valid and reliable satisfaction instrument is likely to contribute to general acceptance of parental satisfaction as a quality performance outcome. Measuring parental satisfaction and evaluating outcomes among several PICUs will, in all probability, provide opportunities for quality programs based on best practices. In other words, PICUs with low satisfaction ratings on certain care aspects may learn from a PICU with high satisfaction ratings on these aspects. Via these best practices PICUs are able to work on continuous collaborative quality improvement.

The limitations of the study should be addressed. First, parents' characteristics were not taken into account, albeit on purpose. The overall aim was to develop a parental satisfaction instrument for the general population in the PICU. Additional questions about family composition and characteristics would have raised the already high number of items in the survey and could have reduced the response rate. This argument is counteracted, however, by a study from Jenkinson and colleagues that reported no significant difference in response rate between a satisfaction survey with 15 items and one with 108 items [36].

Second, the satisfaction items had been generated from the existing literature and the opinions of PICU professionals. It could be argued that, in the initial stage of the developmental process, an explorative study among parents might have been appropriate to identify the satisfaction items. Such a qualitative study might have resulted in other satisfaction items. We believe, however, that the approach we opted for created a firm enough basis for further development.

Third, the overall response rate of $54 \%$ is fairly low. Comparable studies using data collection via mail obtained response rates between $60 \%$ and $70 \%$ [37-39]. Still, we made some efforts to achieve a high response rate, i.e., translating the questionnaire, providing an online submission option, and sending a reminder. The face-to-face approach might be a better method in future studies, since it is associated with a significant higher response compared with mailing the survey [38].

In conclusion, a large group of parents of children admitted to a PICU in The Netherlands provided their perceptions on satisfaction with care topics based on their experiences. These valuable perceptions will make it possible to further develop a satisfaction instrument specifically for the PICU and based on the empowerment of parents. The empirical structure of the satisfaction items and domains can be considered adequate and the reliabilities of the domains are of high level. The results provide a scientific basis for further modification of the instrument. Redundant items that measure the same concept might be eliminated, leaving a still reliable and valid satisfaction instrument for PICU services.

Future research should also include open-ended questions asking parents for suggestions on how care could be improved. These important qualitative data can clarify and complement the quantitative results, and the synergy of these data makes it possible to identify areas to improve clinical practice $[9,40]$. Furthermore, it might be recommended to design satisfaction instruments that allow to discriminate groups of parents such as parents of different cultural backgrounds. Also, parents of children hospitalized for postoperative care are assumed to have different experiences than parents of a child admitted with a lifethreatening condition. Finally, parents of different cultural backgrounds hardly made use of one of the translated versions of questionnaires. Different approaches such as giving the questionnaire face-to-face in their own language might be recommended to increase their participation.

Ultimately, the instrument should be able to provide parents with a tool to collaborate with healthcare professionals in quality improvement of PICU services.

Acknowledgments The authors thank the parents for providing their valuable experiences. Beatrix Elink-Schuurman (B.E.-S) is thanked for her assistance in data collection and the qualitative analysis. Idse Visser and the Dutch PICE study group are thanked for obtaining data from the PICE database. Ko Hagoort is thanked for editorial assistance. This study was partially supported by a grant, SNO-T-0501114, from the Nuts OHRA foundation. The sponsor was not involved in the study design, data collection, analysis, the manuscript, and in the decision to submit the manuscript for publication.

Conflict of interest statement The authors have no financial interest or any other conflict of interest to declare.

Open Access This article is distributed under the terms of the Creative Commons Attribution Noncommercial License which permits any noncommercial use, distribution, and reproduction in any medium, provided the original author(s) and source are credited. 


\section{References}

1. Grol R (2001) Improving the quality of medical care: building bridges among professional pride, payer profit, and patient satisfaction. JAMA 286:25782585

2. Arah OA, Westert GP, Hurst J, Klazinga NS (2006) A conceptual framework for the OECD health care quality indicators project. Int J Qual Health Care 18:5-13

3. Sajid MS, Baig MK (2007) Quality of health care: an absolute necessity for public satisfaction. Int $\mathbf{J}$ Health Care Qual Assur 20:545-548

4. ten Asbroek AH, Arah OA, Geelhoed J, Custers T, Delnoij DM, Klazinga NS (2004) Developing a national performance indicator framework for the Dutch health system. Int J Qual Health Care 16:i65-i71

5. Bijttebier P, Vanoost S, Delva D, Ferdinande P, Frans E (2001) Needs of relatives of critical care patients: perceptions of relatives, physicians and nurses. Intensive Care Med 27:160-165

6. Latour JM, Haines C (2007) Families in the ICU: do we truly consider their needs, experiences and satisfaction? Nurs Crit Care 12:173-174

7. Maxwell KE, Stuenkel D, Saylor C (2007) Needs of family members of critically ill patients: a comparison of nurse and family perceptions. Heart Lung 36:367-376

8. Takman CA, Severinsson EI (2004) The needs of significant others within intensive care-the perspectives of Swedish nurses and physicians. Intensive Crit Care Nurs 20:22-31

9. Haines C, Childs H (2005) Parental satisfaction with paediatric intensive care. Paediatr Nurs 17:37-41

10. Heyland DK, Tranmer JE (2001) Measuring family satisfaction with care in the intensive care unit: the development of a questionnaire and preliminary results. J Crit Care 16:142-149

11. McPherson ML, Sachdeva RC, Jefferson LS (2000) Development of a survey to measure parent satisfaction in a pediatric intensive care unit. Crit Care Med 28:3009-3013

12. Wasser T, Matchett S (2001) Final version of the critical care family satisfaction survey questionnaire. Crit Care Med 29:1654-1655

13. Dodek PM, Heyland DK, Rocker GM, Cook DJ (2004) Translating family satisfaction data into quality improvement. Crit Care Med 32:1922-1927

14. Berenholtz SM, Dorman T, Ngo K, Pronovost PJ (2002) Qualitative review of intensive care unit quality indicators. J Crit Care 17:1-12
15. Latour JM, Hazelzet JA, van der Heijden AJ (2005) Parent satisfaction in pediatric intensive care: a critical appraisal of the literature. Pediatr Crit Care Med 6:578-584

16. Latour JM, Hazelzet JA, Duivenvoorden HJ, van Goudoever JB (2008) Construction of a parent satisfaction instrument: Perceptions of pediatric intensive care nurses and physicians. J Crit Care. doi: 10.1016/j.jcrc.2008.06.002 (in press)

17. Visser I, Dutch PICE Study Group (2008) PICE Report 2003-2005: Dutch pediatric intensive care evaluation. Stichting PICE, Rotterdam

18. Meyer EC, Ritholz MD, Burns JP, Truog RD (2006) Improving the quality of end-of-life care in the pediatric intensive care unit: parents' priorities and recommendations. Pediatrics 117:649-657

19. Meert KL, Briller SH, Schim SM, Thurston CS (2008) Exploring parents' environmental needs at the time of a child's death in the pediatric intensive care unit. Pediatr Crit Care Med 9:623628

20. Latour JM (2008) Parental needs during end-of-life care: one room for improvement. Pediatr Crit Care Med 9:661-662

21. Bouwhuis CB, Moll HA (2003) Determination of ethnicity in children in The Netherlands: two methods compared. Eur J Epidemiol 18:385-388

22. Muthén LK, Muthén MB (2004) Mplus statistical analysis with latent variables. User's guide, 3rd edn. Muthén \& Muthén, Los Angeles

23. Davidson JE, Powers K, Hedayat KM, Tieszen M, Kon AA, Shepard E, Spuhler V, Todres ID, Levy M, Barr J et al (2007) Clinical practice guidelines for support of the family in the patientcentered intensive care unit: American college of critical care medicine task force 2004-2005. Crit Care Med 35:605-622

24. Latour JM (2005) Is family-centred care in critical care units that difficult? A view from Europe. Nurs Crit Care 10:51-53

25. Farrell MF, Frost C (1992) The most important needs of parents of critically ill children: parents' perceptions. Intensive Crit Care Nurs 8:130-139

26. Fisher MD (1994) Identified needs of parents in a pediatric intensive care unit. Crit Care Nurse 14:82-90

27. Kirschbaum MS (1990) Needs of parents of critically ill children. Dimens Crit Care Nurs 9:344-352
28. Scott LD (1998) Perceived needs of parents of critically ill children. J Soc Pediatr Nurs 3:4-12

29. Latour JM, van Goudoever JB, Hazelzet JA (2008) Parent satisfaction in the pediatric ICU. Pediatr Clin North Am 55:779-790

30. Shudy M, de Almeida ML, Ly S, Landon C, Groft S, Jenkins TL, Nicholson CE (2006) Impact of pediatric critical illness and injury on families: a systematic literature review. Pediatrics 118:S203-S218

31. Diaz-Caneja A, Gledhill J, Weaver T, Nadel S, Garralda E (2005) A child's admission to hospital: a qualitative study examining the experiences of parents. Intensive Care Med 31:12481254

32. Carter MC, Miles MS (1989) The Parental stressor scale: pediatric intensive care unit. Matern Child Nurs J 18:187-198

33. Board R (2004) Father stress during a child's critical care hospitalization. J Pediatr Health Care 18:244-249

34. Board R, Ryan-Wenger N (2003) Stressors and stress symptoms of mothers with children in the PICU. J Pediatr Nurs 18:195-202

35. Melnyk BM, Alpert-Gillis L, Feinstein NF, Crean HF, Johnson J, Fairbanks E, Small L, Rubenstein J, Slota M, CorboRichert B (2004) Creating opportunities for parent empowerment: program effects on the mental health/coping outcomes of critically ill young children and their mothers. Pediatrics 113:e597e607

36. Jenkinson C, Coulter A, Reeves R, Bruster S, Richards N (2003) Properties of the Picker Patient Experience questionnaire in a randomized controlled trial of long versus short form survey instruments. J Public Health Med 25:197-201

37. Asch DA, Jedrziewski MK, Christakis NA (1997) Response rates to mail surveys published in medical journals. J Clin Epidemiol 50:1129-1136

38. Sitzia J, Wood N (1998) Response rate in patient satisfaction research: an analysis of 210 published studies. Int $\mathbf{J}$ Qual Health Care 10:311-317

39. Badger F, Werrett J (2005) Room for improvement? Reporting response rates and recruitment in nursing research in the past decade. J Adv Nurs 51:502-510

40. Rusinova K, Pochard F, Kentish-Barnes N, Chaize M, Azoulay E (2009) Qualitative research: adding drive and dimension to clinical research. Crit Care Med 37:S140-S146 